\title{
Evaluation of a point-of use water purification system (Llaveoz) in a rural setting of Chiapas, Mexico
}

\begin{abstract}
Access to potable water is a priority for highly-marginalized rural communities of Chiapas, Mexico where consumption of poorly sanitized water has fostered severe diarrheal diseases among children. Interventions aimed to reduce contaminants present in water are necessary to reduce morbidity and mortality rates. In this work we evaluated the efficiency of a point of use water purification system, Llaveoz, to eradicate total coliform (TC) bacteria and diarrheagenic E. coli (DEC) strains in 62 paired water samples obtained from households during the dry and rainy season. TC was determined by the membrane filtration method whereas DEC strains were evaluated by a multiplex PCR approach. After Llaveoz treatment, water samples collected during the dry season $(\mathrm{N}=20)$ had an $80.3 \%$ reduction of TC counts ( $<<0.05)$. Similarly, TC were significantly reduced $(72.3 \%$, $(p<0.05))$ in water samples treated during the rainy season $(\mathrm{N}=42)$. A total of 28 E. coli strains were isolated of which $14.3 \%(\mathrm{~N}=4)$ were identified as DEC strains (ETEC $(\mathrm{N}=2)$, EAEC $(\mathrm{N}=1)$ or EIEC $(\mathrm{N}=1)$ ) in untreated water samples. Llaveoz-treated water did not contain DEC strains. Thus, the Llaveoz system represents an alternative method to obtain more pure water in regions where potable water sources are not available.
\end{abstract}

Keywords: Chiapas, diarrheagenic E. coli, llaveoz, water purification system
Volume I Issue 3 - 2014

\section{Javier Gutierrez-Jimenez, Florence Cassassuce, Liliana Martinez-de la Cruz, Jose Alexis De Aquino-Lopez, Juan Antonio Hernandez-Shilon, Maria Adelina Schlie- Guzman, Jorge EVidal \\ University of Science and Arts of Chiapas, Mexico}

Correspondence: Javier Gutierrez-Jimenez, University of Science and Arts of Chiapas, Libramiento norte poniente\#I I50, Col. Lajas Maciel,Tuxtla Gutierrez, Chiapas, Mexico, Tel +529616170440/4303, Email javier.gutierrez@unicach.mx

Received: May 19, 20I4 | Published: June 24, 2014
Abbreviations: TC, total coliforms; UV, ultraviolet; E. coli, Escherichia coli; DEC, diarrheagenic Escherichia coli; EPEC, enteropathogenic E. coli; ETEC. enterotoxigenic E. coli; STEC, shiga toxin-secreting E. coli; EIEC, enteroinvasive E. coli; EAEC, enteroaggregative E. coli; $\mathrm{CFU}$, colony forming units; SD, standard deviation; PCR, polymerase chain reaction.

\section{Introduction}

For over five years the state of Chiapas, Mexico, has occupied the first place of extreme poverty in the country. Its inhabitants have an educational delay, limited access to health care services, social security and to basic household services such as potable water. ${ }^{1}$ During 2008, the mortality rate due to diarrhea among chiapanecan children under five years old was 42.8 deaths per 100000 live births, more than threefold above the national rate $(12.1) .{ }^{2}$ Stevens et al., ${ }^{3}$ showed that risk factors such as malnutrition, contaminated water, poor sanitation, and indoor air pollution increases child mortality in Southern (16\%) Mexico, more than in the Northern region $(<2 \%){ }^{3}$ Despite the incidence of diarrheal illness as one of the ten leading causes of children mortality and morbidity in Chiapas, ${ }^{2,3}$ specific etiologic agents are not investigated perhaps for a lack of resources. In effort to begin evaluating agents and risk factors implicated in these cases, we recently demonstrate a high prevalence of malnutrition and intestinal parasites among children from marginalized municipalities of Chiapas. ${ }^{4}$

The inhabitants of Oxchuc, Chiapas, one of Mexico's most marginalized municipalities, obtain potable water for household use from natural sources such as rain, wells or rivers. Since open defecation is a common practice among inhabitants of Oxchuc and other marginalized municipalities of Chiapas, water sources are prone to contamination by feces containing bacterial pathogens associated with water-borne diseases. This may account for the documented high mortality rates due to diarrheal diseases in the area. ${ }^{2,3}$

In order to improve water quality in resources-limited regions, affordable methods to disinfect water need to be engineered. Water for human consumption must have an appropriate quality in order to prevent and avoid transmission of gastrointestinal pathogens. ${ }^{5}$ These systems should demonstrate effectiveness in removing potential human pathogens from water samples such as the presence of $E$. coli strains, a biological indicator of fecal contamination. Thus, the objective of this study was to evaluate the efficacy of a UV radiationbased water disinfection system, hereafter called Llaveoz, to eliminate total coliforms and pathogenic E. coli strains, in water utilized for human consumption in a rural zone of Chiapas, Mexico.

\section{Materials and methods}

\section{Study zone}

This study was carried out in the Lelenchij locality, Oxchuc, Chiapas, Mexico, which is located at 1,900 meters above the sea level, in the Altos Tsotsil Tseltal zone. The community had 807 inhabitants in $2013,99.8 \%$ of which do not have access to health care services. Their houses in general have electricity $(94.3 \%)$ but $99.2 \%$ and $86.5 \%$ of them do not have sources of potable water and sewage, respectively and $41.4 \%$ of households have earthen floor. $^{6}$

\section{Llaveoz water disinfection system}

The Llaveoz ${ }^{\mathrm{TM}}$ water disinfection system (patent US2011/0215037 A1) consists in a plastic faucet which is placed at the base of a water container used at home for water storage; the faucet contains an ultraviolet light bulb UVC type which uses electricity (110V or $12 \mathrm{~V})$. Its light goes on when the faucet is opened in order to pour 
clean water. To eliminate suspended solids, parasites and bacteria, the faucet is connected to a microfiltration cartridge which contains polypropylene membranes with $0.1 \mu \mathrm{m}$ pore diameter. In vitro studies demonstrate that Llaveoz is able to eliminate $~ 99,100 \%$ and $\sim 99 \%$ of parasites, bacteria and virus, respectively. Llaveoz purification system is fabricated and distributed to rural and peri-urban communities by EOZ group, a non-profit organization funded by Flor Cassassuce with a self-funding mechanism. ${ }^{7}$ An operational and maintenance procedure of this system was presented to the municipality's authorities, and to families of Lelenchij, Chiapas. Once they were trained in how to use it, Llaveoz was donated to these families and added this technology to the purification regimen by boiling of water that they usually use (Figure 1). Free and informed consent of the participants or their legal representatives was obtained and the study protocol was approved by the ethics committee at the Universidad de Ciencias y Artes de Chiapas, Chiapas, Mexico, Protocol \# 09012010 , approval date September 6th, 2010. We interviewed mothers of the families to obtain information such as sources of drinking water in the household, type of floor, whether they have latrines or not, education level of the mother, and the method (if any) they utilized to sterilize water prior the introduction of Llaveoz. Data were collected through a translator, who established communication with the participants in their native language (tsotsil).
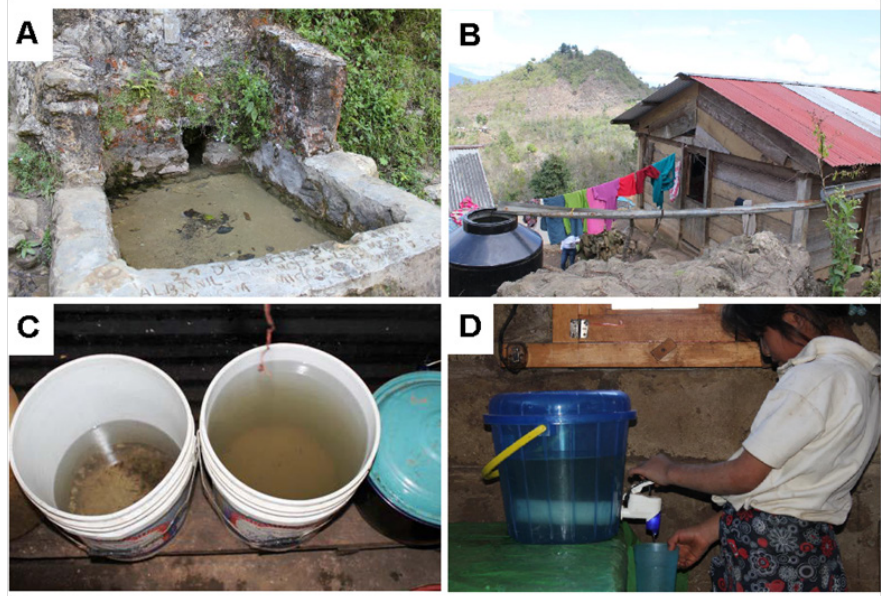

Figure I Methods for collection and storage of water in Lelenchij, Chiapas, Mexico. A) A spring delimited by concrete and stone B) Water rain directly collected in a water tank C) Water is collected from nearby rivers, and stored, in buckets $D$ ) $A$ child using the Llaveoz water purification system.

\section{Quantification of total coliforms (TC)}

Total coliforms were quantified in pairwise samples of water utilized for human consumption, before and after treatment with the Llaveoz system as follows: $500 \mathrm{~mL}$ of water were collected from the upper section of the plastic water container (untreated water), and from the water dispensed when opening the faucet of the purification system (Llaveoz-treated water). Water samples were collected in sterile $24 \mathrm{oz}$. bags (Whirl-Pak ${ }^{\circledR}$ ) and stored in ice during the transport to the laboratory. Once in the lab, TC quantification was immediately performed utilizing the standard membrane filtration protocol, according to both Mexican Official Norm NOM-180-SSA1-1998 ${ }^{8}$ and the US FDA method. ${ }^{9}$ Samples of $100 \mathrm{~mL}$ of untreated and treated water were filtered through a gridded sterile nitrocellulose membrane with $0.45 \mu \mathrm{m}$ pores (Millipore). The membranes were set on top of a pad with m-Endo broth (Millipore) in $47 \mathrm{~mm}$ sterile Petri dishes (Millipore) and incubated at $35^{\circ} \mathrm{C}$ for 20 hours. Dark-red with green metallic surface sheen colonies indicative of TC that grew on the agar plates were counted, and the density of coliforms was calculated following the above mentioned guidelines. A total of $1000 \mathrm{TC} / 100 \mathrm{~mL}$ was the upper limit of detection of this assay. Results were interpreted according to criteria established by both the Mexican Official Norm NOM-127-SSA1-19945 and the U.S. Environmental Protection Agency, which sets it at zero in water for human consumption. ${ }^{10}$

\section{Identification of diarrheagenic E. coli (DEC)}

Colonies suspected to be $E$. coli were re-isolated on MacConkey agar plates and further identified to the species level using the Api20E system (BioMrieux). The different diarrheagenic categories of $E$. coli were investigated by multiplex PCR targeting virulence genes carried by the specific pathotypes as follows: the $b f p A$ and eaeA genes were used to identify enteropathogenic E. coli (EPEC) strains; the genes $s t$ and $l t$ identified enterotoxigenic $E$. coli (ETEC) strains, stx 1 and stx 2 were utilized as markers for Shiga toxin-secreting $E$. coli (STEC) strains whereas the ial gene identified enteroinvasive E. coli (EIEC) strains. ${ }^{11}$ The aggR, AA PROBE and aap genes were specific molecular markers for enteroaggregative E. coli (EAEC) strains. ${ }^{12}$ Bacterial DNA was obtained by transferring 1 to 2 colonies to nuclease-free water (USB $\left.{ }^{\circ}, \mathrm{USA}\right)$, and bacterial suspensions were boiled for 10 minutes. Primers and reaction conditions were similar to those previously published. ${ }^{11,12}$ Reactions were carried out with GoTaq ${ }^{\circledR}$ Green Master Mix, (Promega) in a final volume of $25 \mu \mathrm{L}$. PCR products were resolved by electrophoresis utilizing $1 \mathrm{X}$ TAE buffer (400mM Tris-acetate, $10 \mathrm{mM}$ EDTA, Promega) on 2.5\% agarose gels. Gels were stained with ethidium bromide $(0.5 \mu \mathrm{g} / \mathrm{mL})$ and the PCR products were observed in an UV transilluminator (VilberLourmat, France). Normal flora E. coli ATCC 25922 strain, which does not carry any of those target genes, was used as a negative control. Reference strains of all DEC strains included in this study were EPEC E2348/69 (O127:H6), ETEC H10407 (O78:H11), EIEC E11 (O124 NM), STEC EDL933 (O157:H7) and EAEC 042 (O44:H18). These strains were generously provided by Dr. Maria Teresa Estrada-Garcia and Dr. Fernando Navarro-Garcia from CINVESTAV, Mexico, and used as positive controls.

\section{Statistical analysis}

Sociodemographic data, total coliform quantification, and the frequency of $E$. coli pathogenic types were analyzed through descriptive statistics (mean, and standard deviation). The efficiency of the Llaveoz system was assessed with the Student's $t$ test for paired samples, with a significance level of $0.05 \%$. All analyses were performed using the SPSS software, version 20 (Armonk, New York: IBM Corp.).

\section{Results and discussion}

\section{Sociodemographic data}

Forty-four families whom agreed on participating in this study were included. They obtain their drinking water from springs or rain and it is kept in water tanks, buckets, pots, or barrels (Figures 1 (A-C). Most of the households have concrete floor (74.4\%); the remainder have earth-floors $(25.6 \%) ; 84.6 \%$ of them have latrines. Most mothers attended to the elementary school but did not finish it; $\sim 82.5 \%$, know how to read and write whereas the remainder $(\sim 17.5 \%)$ are analphabets. A total of $81.9 \%$ of households utilize a method to disinfect their drinking water. Boiling $(70.5 \%)$ is the most utilized followed by the use of chloride (11.4\%). In the remaining households (18.2\%) water is drank as they collected with no treatment at all. 
The Social Development Ministry of Mexico classified the Lelenchij locality as one with a high marginalization level. ${ }^{6}$ Among other relevant needs they lack, families living in this locality did not have access to potable water thereby they have to utilize water from natural sources. This water is contaminated with fecal bacteria and, to a lower extent, with DEC strains (Figure 2). A basic practice that has helped these families to reduce the bacterial load is by boiling the water before they drink it $(70.5 \%)$. However, our microbiological studies revealed that even when more than $\sim 80 \%$ of those families utilize a disinfection method, all water samples were contaminated with TC and pathogenic E. coli strains (Table 1). In a similar fashion, a study conducted in rural areas of Lesotho, Africa, revealed that $97 \%$ of water samples obtained from natural sources contained total coliforms (for example, a mean of $1.51 \times 10^{3} \mathrm{CFU} / 100 \mathrm{ml}$ in unprotected springs) ${ }^{13}$ whereas another study, carried out in rural areas of Indonesia, showed that $51 \%$ of contained water had E. coli. ${ }^{14}$

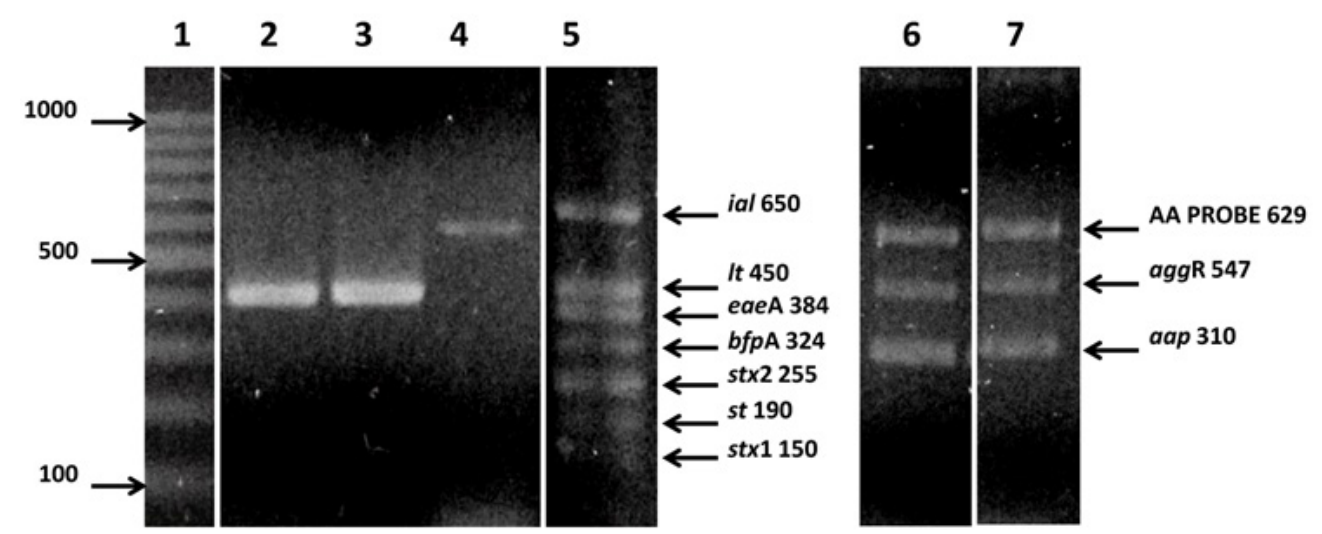

Figure 2 PCR amplification of genetic markers of diarrheagenic Escherichia coli strains isolated from untreated-Llaveoz water in Lelenchij, Mexico. Lanes: I, I00bp molecular weight marker; 2-3, It gene amplified from AI IF3 and AI 3F3 E. coli strains; 4, ial gene amplified from A30F3 E. coli strain; 6, AA PROBE, aggR and aap genes amplified from A38F3 E. coli strain; 5 and 7, PCR products of reference DEC strains (EIEC, ETEC, EPEC, and STEC (lane 5) and EAEC (lane 7) strains).

Table I Total coliforms (TC) in untreated and Llaveoz-treated water during the dry and rainy season in Lelenchij, Mexico

\begin{tabular}{|c|c|c|c|c|c|}
\hline \multicolumn{6}{|l|}{ Dry season } \\
\hline Household & TC in untreated Llaveoz water (CFU/ $/ 00 \mathrm{ml})$ & TC in Llaveoz-treated water (CFU/100ml) & E. coli & DEC & $p$ \\
\hline 6 & 476 & 416 & A & $\mathrm{N}$ & \\
\hline 10 & 307 & 42 & $\mathrm{P}$ & $\mathrm{N}$ & \\
\hline 1 & 200 & 0 & $A$ & $\mathrm{~N}$ & \\
\hline 2 & 200 & 1 & $\mathrm{P}$ & $\mathrm{N}$ & \\
\hline 4 & 200 & 13 & $A$ & $\mathrm{~N}$ & \\
\hline 5 & 200 & 8 & $\mathrm{P}$ & $\mathrm{N}$ & \\
\hline 7 & 200 & 18 & $P$ & $\mathrm{~N}$ & \\
\hline 8 & 200 & 0 & $A$ & $N$ & \\
\hline 9 & 200 & 4 & A & $N$ & \\
\hline 19 & 200 & 23 & $P$ & $N$ & \\
\hline 13 & 190 & 0 & $A$ & $N$ & $1.00575 \mathrm{E}-5$ \\
\hline 3 & 84 & 0 & $P$ & $N$ & \\
\hline 12 & 80 & I & $P$ & $N$ & \\
\hline 11 & 78 & 0 & $P$ & $N$ & \\
\hline 15 & 38 & I & $P$ & $N$ & \\
\hline 17 & 35 & 5 & A & $N$ & \\
\hline 16 & 18 & 42 & $P$ & $N$ & \\
\hline 14 & 12 & 2 & $A$ & $N$ & \\
\hline 20 & 8 & 0 & $A$ & $N$ & \\
\hline 18 & 6 & 0 & A & $N$ & \\
\hline Mean & 146.6 & 28.8 & & & \\
\hline
\end{tabular}


Table Contiued...

\begin{tabular}{|c|c|c|c|c|c|}
\hline \multicolumn{6}{|c|}{ Rainy season } \\
\hline 2 & 1000 & 100 & $A$ & $\mathrm{~N}$ & \\
\hline 5 & 1000 & 25 & A & $\mathrm{N}$ & \\
\hline 24 & 1000 & 5 & $P$ & EIEC & \\
\hline 25 & 1000 & 1000 & $P$ & $\mathrm{~N}$ & \\
\hline 32 & 1000 & 800 & A & $\mathrm{N}$ & \\
\hline 37 & 1000 & 15 & A & $\mathrm{N}$ & \\
\hline 39 & 1000 & 500 & $P$ & $\mathrm{~N}$ & \\
\hline $4 I$ & 1000 & 300 & A & $\mathrm{N}$ & \\
\hline 29 & 900 & 800 & A & $\mathrm{N}$ & \\
\hline 26 & 800 & 19 & $P$ & $\mathrm{~N}$ & \\
\hline 28 & 800 & 700 & $A$ & $\mathrm{~N}$ & \\
\hline 31 & 800 & 18 & $P$ & EAEC & \\
\hline 33 & 800 & 10 & $P$ & $\mathrm{~N}$ & \\
\hline 40 & 800 & 300 & $P$ & $\mathrm{~N}$ & \\
\hline 42 & 800 & 250 & A & $\mathrm{N}$ & \\
\hline 22 & 700 & 400 & $A$ & $\mathrm{~N}$ & \\
\hline 35 & 700 & 2 & A & $\mathrm{N}$ & \\
\hline 36 & 700 & 0 & A & $\mathrm{N}$ & \\
\hline 38 & 700 & 300 & A & $\mathrm{N}$ & \\
\hline 14 & 600 & 0 & $P$ & $\mathrm{~N}$ & \\
\hline 27 & 600 & 74 & $P$ & $\mathrm{~N}$ & \\
\hline 10 & 500 & 20 & $P$ & ETEC & I.30433E-9 \\
\hline 11 & 500 & 150 & $P$ & $N$ & \\
\hline 12 & 500 & 0 & $P$ & ETEC & \\
\hline 13 & 500 & 0 & $A$ & $\mathrm{~N}$ & \\
\hline 20 & 500 & 25 & $P$ & $\mathrm{~N}$ & \\
\hline 23 & 400 & 0 & $P$ & $\mathrm{~N}$ & \\
\hline 16 & 300 & 120 & $P$ & $\mathrm{~N}$ & \\
\hline 19 & 300 & 0 & $P$ & $\mathrm{~N}$ & \\
\hline 6 & 200 & 0 & $A$ & $\mathrm{~N}$ & \\
\hline 34 & 200 & 13 & $A$ & $\mathrm{~N}$ & \\
\hline 18 & 110 & 9 & $A$ & $\mathrm{~N}$ & \\
\hline 8 & 100 & 2 & $P$ & $\mathrm{~N}$ & \\
\hline I & 60 & 60 & $A$ & $\mathrm{~N}$ & \\
\hline 3 & 60 & 25 & $A$ & $\mathrm{~N}$ & \\
\hline 15 & 60 & 0 & $A$ & $\mathrm{~N}$ & \\
\hline 4 & 50 & 50 & $A$ & $N$ & \\
\hline 7 & 40 & 5 & $A$ & $\mathrm{~N}$ & \\
\hline 17 & 30 & 8 & $A$ & $\mathrm{~N}$ & \\
\hline 21 & 23 & 3 & $A$ & $\mathrm{~N}$ & \\
\hline 9 & 20 & 25 & $P$ & $\mathrm{~N}$ & \\
\hline 30 & 3 & 0 & & & \\
\hline Mean & 527.5 & 146 & & & \\
\hline
\end{tabular}

TC, total coliforms; CFU, colony forming units;A, absent; P, present; $\mathrm{N}$, negative; EIEC, enteroinvasive E. coli; EAEC, enteroaggregative E. coli; ETEC, enterotoxigenic E. coli.

Citation: Gutierrez-Jimenez J, Cassassuce F, Cruz LM, et al. Evaluation of a point-of use water purification system (Llaveoz) in a rural setting of Chiapas, Mexico.J Microbiol Exp. 2014; I (3):100-105. DOI: 10.15406/jmen.2014.01.000I5 
Although water boiling has proved to be an efficient method for eliminating $E$. coli, ${ }^{15}$ water is still prone to contamination if it is handled with hands or if unclean containers are used to store it; ${ }^{16}$ these two factors may likely account for the fact that all water samples were contaminated.

\section{Significant reduction of TC counts in water samples treated with the Llaveoz water purification system}

A total of 62 paired water samples were obtained from those households, (untreated and Llaveoz-treated) throughout the duration of the study. Twenty water samples were collected during the dry season, and 42 during in the rainy season. TC was quantified in each of them (Table 1). All samples collected during the dry season, prior to Llaveoz treatment, were contaminated with TC. Our microbiological studies detected water samples with $6 \mathrm{CFU} / 10 \mathrm{ml}$ and families drinking water containing as much as $476 \mathrm{CFU} / 100 \mathrm{ml}$ of TC. The mean of TC in water samples collected during the dry season was $146 \mathrm{CFU} / 100$ $\mathrm{ml}(\mathrm{SD} \pm 119.17 \mathrm{CFU} / 100 \mathrm{ml}$ ) (Table 1). Llaveoz-treated samples, however, presented a mean TC count of $28 \mathrm{CFU} / 100 \mathrm{ml}(\mathrm{SD} \pm 92.08$ $\mathrm{CFU} / 100 \mathrm{ml}$ ) which represented a statistically significant reduction of $80.3 \%$ of TC $(\mathrm{p}<0.05)$. Moreover, in $35 \%(\mathrm{~N}=7)$ of water samples, TC were completely eradicated post Llaveoz treatment.

Similarly, all water samples collected during the rainy season were found contaminated by TC. In comparison to the dry season, most water samples from the rainy season contained from twice to tenfold the TC and as much as $1 \times 10^{3} \mathrm{CFU} / 100 \mathrm{ml}$ of TC. This increased TC counts in untreated water samples collected from the rainy season was statistically significant $(p<0.05)$. The mean TC counts in untreated water samples from the rainy season were $527 \mathrm{CFU} / 100 \mathrm{ml}$ ( $\mathrm{SD} \pm 361.26)$. We observed, however, a significant $72.3 \%(\mathrm{p}<0.05)$ reduction of TC in Llaveoz-treated water samples with a mean of 146 $\mathrm{CFU} / 100 \mathrm{ml}$ (SD \pm 255.5 ) (Table 1). Llaveoz completely eliminated $\mathrm{TC}$ in $21.4 \%(\mathrm{~N}=9)$ of samples. In some cases, Llaveoz was able to produce water with microbiological quality for human consumption in samples contaminated up to $700 \mathrm{CFU} / 100 \mathrm{ml}$. Whereas untreated water samples collected from the rainy season contained higher levels of TC, treatment of water samples collected from both seasons with Llaveoz eliminated TC with similar efficiency $(p=0.052)$.

An interesting observation we made was that the mean counts of TC during the rainy season was significantly higher when compared to the dry season $(\mathrm{p}<0.05)$. This is probably due to the fact that during June, 2011 more rainfall $(\sim 234.8 \mathrm{~mm})$ was registered, with respect to March, 2011 ( 42 mm), in our study area ${ }^{17}$ and thus cross contamination with fecal matter from open defecation practices is more likely to occur. Moreover, during the rainy season septic tanks are filtered and dragged towards the bodies of water, also causing fecal contamination. ${ }^{18}$

\section{Detection of diarrheogenic strains of E. coli (DEC)}

Whereas no E. coli strains were identified in Llaveoz-treated water samples, in untreated water samples $(\mathrm{N}=62), 28$ of them contained $E$. coli strains which represented $45.1 \%$. These results further support that at least half of untreated water samples will contain fecal contamination. Our molecular studies utilizing a multiplex PCR approach identified 4 DEC strains (14.3\%) whereas the rest $E$. coli strains $(\mathrm{N}=24)$ did not carry any of the target virulence genes. Our studies isolated and identified 2 enterotoxigenic E. coli strains (ETEC) encoding the $l t$ gene but not the st gene. A typical enteroaggregative E. coli strain (EAEC) was also identified (AA Probe $(+), \operatorname{aggR}(+)$ and app $(+))$. An enteroinvasive E. coli strain (EIEC) encoding the ial gene was also detected (Figure 2). No other pathogenic type, i.e. EPEC, EHEC or STEC, was detected in those water samples. Thus, water utilized for human consumption in some households contains pathogenic DEC strains; these strains were eradicated by treating the water with Llaveoz system.

DEC strains $(\mathrm{N}=4(14 \%))$ were isolated from untreated water samples whereas water samples that had been treated with Llaveoz did not contain any DEC strain. The pathogen type ETEC $(\mathrm{N}=2 / 4)$ was the most common, followed by EAEC and EIEC $(\mathrm{N}=1$ isolate each). Talukdar et al., ${ }^{19}$ also found ETEC as the most frequent pathotype in water samples from Bangladesh, although at a higher frequency $(68 \% ; \mathrm{N}=11 / 16) .{ }^{19}$ ETEC is recognized as one of the most prevalent etiologic agents that cause diarrhea in infants in rural zones in Mexico. ${ }^{20}$ ETEC has also been pointed out, along with EAEC, as the agents more frequently causing the traveler's diarrhea of American citizens that visit Mexico, with a higher frequency of ETEC at hotter temperatures. ${ }^{21}$ Although a vaccine against ETEC has been developed, based on the thermo-sensitive toxin, Behrens et al., ${ }^{22}$ showed that this vaccine has not been effective in protecting travelers that visit Mexico and Guatemala. ${ }^{22}$

This intervention study demonstrated that the Llaveoz system significantly reduced the quantity of total coliforms in contaminated water, although not to acceptable levels for human consumption. ${ }^{5,10}$ It is clear from our studies that Llaveoz can completely eradicate TC bacteria in water samples contaminated with up to $700 \mathrm{CFU} / 100 \mathrm{ml}$. The observations that in some water samples containing the same amount of TC, (i.e. $700 \mathrm{CFU} / 100 \mathrm{ml}$ ), the Llaveoz system either complete removed TC or reduced the TC load might suggest that users were not utilizing the system properly. For example, some users might not have provided the system with proper service including periodic backwash of filter. Poor hygienic habits among inhabitants of this rural community may also account for the failure of Llaveoz to completely remove TC bacteria.

Besides reducing the TC bacterial load in most water samples, Llaveoz completely eradicated the presence of potentially pathogenic DEC strains. A study performed in Tanzania showed that $41 \%$ of the people who had contact with water or food in their households, carried virulent $E$. coli strains on their hands..$^{23}$ Thus, it is desirable to promote actions and conducts that encourage health care from an early age (e.g., in schools), in order to reduce water-borne infections. ${ }^{24}$

Another factor that hindered the complete removal of TC from water samples by the Llaveoz system was that some households experienced blackouts during sampling process, in the absence of electricity the UV source of Llaveoz does not work (households 6, 16 (dry season); 22, 25, 28 and 29 (rainy season), (Table 1). In rural zones of Africa, house-made systems for obtaining purified water, that do not require electricity, have been tested; water is filtered through such materials as sand, gravel, zeolite, ceramic, and silver, which efficiently eliminate coliforms (90\%-100\%). ${ }^{25}$ Another approach to obtain safe water in developing countries is by means of the solar disinfection (SODI) technology, in which water is placed into transparent plastic bottles and then exposes to sunlight. ${ }^{26} \mathrm{~A}$ study made in Ethiopia showed that SODI technology was able to inactivate fecal coliforms from water for less than four hours to sunlight exposure; ${ }^{27}$ however, the efficiency depends of weather conditions. ${ }^{28}$ There is also a portable and efficient system for water purification -LifeStraw-, developed for field workers, who need to drink water from surface sources. In this study, Elsanousi et al., ${ }^{29}$ showed that participants who use the LifeStraw experienced minor events of diarrhea compared to whom did not use this device (15.3 vs. $2.3 \%) .^{29}$ 


\section{Conclusion}

Our intervention pilot study demonstrated that the Llaveoz water purification system can be an alternative for obtaining purified water in Lelenchij, Oxchuc, Chiapas, as well as in other marginalized regions of Chiapas; a previous study in this region showed that only $31 \%$ of water samples were suitable for human consumption. ${ }^{30}$ Although laboratory tests have shown that Llaveoz is able to purify water for human consumption in the laboratory, our study showed that this ability was not achieved at the field level. However, it is necessary to continue with studies involving a greater number of households; to continue training users on the maintenance of the Llaveoz system and design a Llaveoz system working with an alternative source of energy. All these in order to get purified water and diminish diarrhea ${ }^{31}$ which is the main cause of child mortality in Chiapas.

\section{Acknowledgments}

The authors appreciate the time and support from families of Lelenchij, Mexico enrolled in this study. Special thanks to Cecilia Lopez-Sanchez, Lelenchij chairperson as well as her staff by their valuable assistance. Financial support for this project was generously granted by the Instituto Carlos Slim de la Salud, as well as from the Programa multidisciplinario de atencion comunitaria a municipios con alto grado de marginacion de la Universidad de Ciencias y Artes de Chiapas.

\section{Conflicts of interest}

Authors declare that there is no conflict of interest.

\section{References}

1. http://www.coneval.gob.mx/Paginas/principal.aspx

2. http://www.sinais.salud.gob.mx/indicadores/basicos.html

3. Stevens G, Dias RH, Thomas KJ, et al. Characterizing the epidemiological transition in Mexico: national and subnational burden of diseases, injuries, and risk factors. PLoS Med. 2008;5(6):e125.

4. Gutierrez-Jimenez J, Torres-Sanchez MG, Fajardo-Martinez LP, et al Malnutrition and the presence of intestinal parasites in children from the poorest municipalities of Mexico. J Infect Dev Ctries. 2013;7(10):741747

5. http://www.salud.gob.mx/unidades/cdi/nom/m127ssa14.html

6. http://www.microrregiones.gob.mx/catloc/contenido. aspx?refnac $=070640019$

7. http://agualimpia.mx/fichas-tecnicas.php

8. http://www.salud.gob.mx/unidades/cdi/nom/180ssa18.html

9. Hammack TDM, Feng P, Ge B, et al. FDA's bacteriological analytical manual; 2009

10. http://water.epa.gov/drink/contaminants/index.cfm\#content

11. Lopez-Saucedo C, Cerna JF, Villegas-Sepulveda N, et al. Single multiplex polymerase chain reaction to detect diverse loci associated with diarrheagenic Escherichia coli. Emerg Infect Dis. 2003;9(1):127131 .

12. Cerna JF, Nataro JP, Estrada-Garcia T. Multiplex PCR for detection of three plasmid-borne genes of enteroaggregative Escherichia coli strains. $J$ Clin Microbiol. 2003;41(5):2138-140.

13. Gwimbi P. The microbial quality of drinking water in Manonyane community: Maseru District (Lesotho). Afr Health Sci. 2011;11(3):474 480
14. Sodha SV, Menon M, Trivedi K, et al. Microbiologic effectiveness of boiling and safe water storage in South Sulawesi, Indonesia. $J$ Water Health. 2011;9(3):577-585.

15. Brown J, Sobsey MD. Boiling as household water treatment in Cambodia: a longitudinal study of boiling practice and microbiological effectiveness. Am J Trop Med Hyg. 2012;87(3):394-398.

16. Wright J, Gundry S, Conroy R. Household drinking water in developing countries: a systematic review of microbiological contamination between source and point-of-use. Trop Med Int Health. 2004;9(1):106-117.

17. ht t p://smn.cna.gob.mx/index.php?option=com content\&view $=$ article\&id $=42 \&$ Itemid $=75$

18. Barrell RA, Rowland MG. The relationship between rainfall and well water pollution in a West African (Gambian) village. J Hyg (Lond). 1979;83(1):143-150.

19. Talukdar PK, Rahman M, Rahman M, et al. Antimicrobial resistance, virulence factors and genetic diversity of Escherichia coli isolates from household water supply in Dhaka, Bangladesh. PLoS One. 2013;8(4):e61090.

20. Cravioto A, Reyes RE, Ortega R, et al. Prospective study of diarrhoeal disease in a cohort of rural Mexican children: incidence and isolated pathogens during the first two years of life. Epidemiol Infect. 1988;101(1):123-134.

21. Paredes-Paredes M, Okhuysen PC, Flores J, et al. Seasonality of diarrheagenic Escherichia coli pathotypes in the US students acquiring diarrhea in Mexico. J Travel Med. 2011;18(2):121-125.

22. Behrens RH, Cramer JP, Jelinek T, et al. Efficacy and safety of a patch vaccine containing heat-labile toxin from Escherichia coli against travellers' diarrhoea: a phase 3, randomised, double-blind, placebocontrolled field trial in travellers from Europe to Mexico and Guatemala. Lancet Infect Dis. 2013;14(3):197-204.

23. Mattioli MC, Boehm AB, Davis J, et al. Enteric pathogens in stored drinking water and on caregiver's hands in Tanzanian households with and without reported cases of child diarrhea. PLoS One. 2014;9(1):e84939.

24. Lee A. Health-promoting schools: evidence for a holistic approach to promoting health and improving health literacy. Appl Health Econ Health Policy. 2009;7(1):11-17.

25. Mwabi JK, Mamba BB, Momba MN. Removal of Escherichia coli and faecal coliforms from surface water and groundwater by household water treatment devices/systems: a sustainable solution for improving water quality in rural communities of the Southern African development community region. Int J Environ Res Public Health. 2012;9(1):139-170.

26. McGuigan KG, Conroy RM, Mosler HJ, et al. Solar water disinfection (SODIS): a review from bench-top to roof-top. J Hazard Mater. 2012;235(236):29-46.

27. Dessie A, Alemayehu E, Mekonen S, et al. Solar disinfection: an approach for low-cost household water treatment technology in Southwestern Ethiopia. J Environ Health Sci Eng. 2014;12(1):25.

28. Mustafa A, Scholz M, Khan S, et al. Application of solar disinfection for treatment of contaminated public water supply in a developing country: field observations. $J$ Water Health. 2013;11(1):135-145.

29. Elsanousi S, Abdelrahman S, Elshiekh I, et al. A study of the use and impacts of LifeStraw in a settlement camp in southern Gezira, Sudan. $J$ Water Health. 2009;7(3):478-483.

30. Sanchez-Perez HJ, Vargas-Morales MG, Mendez-Sanchez JD. Bacteriological quality of human drinking water in high-margination zones in Chiapas. Salud Publica Mex. 2000;42(5):397-406.

31. Luby SP. Quality of drinking water. BMJ. 2007;334(7597):755-756. 